\title{
Unfettering discussions about social justice: the role of conversational prompts in discussions about mathematics education for Indigenous students
}

\author{
Tamsin Meaney $^{1}$ (D) A. B. Fyhn² S. R. W. Graham ${ }^{3}$
}

Accepted: 13 July 2021 / Published online: 21 August 2021

(c) The Author(s) 2021

\begin{abstract}
To increase possibilities for listening respectfully to Indigenous educators, there is a need to identify conversational prompts which are used to raise alternative views of social justice about mathematics education for Indigenous students. Using Nancy Fraser's description of abnormal social justice, an analysis was made of transcripts from round table sessions, at an Indigenous mathematics education conference. This analysis identified a number of conversational prompts that enabled shifts from normal to abnormal discussions about social justice. Normal discussions exhibited assumptions in which mathematics was valued as a Western domain of knowledge; cultural examples could be used as vehicles to teach mathematics; and decisions about education for Indigenous students should be made by external authorities. In abnormal discussions, these assumptions were queried and alternative possibilities arose. The conversational prompts, which initiated this querying, occurred in a number of ways, including the telling of stories and the asking of questions that either directly or indirectly challenged normal justice discourses about Indigenous students' learning of mathematics. Identifying conversational prompts can assist non-Indigenous mathematics educators, who wish to be allies, to challenge their own and others' assumptions about normal social justice issues related to mathematics education for Indigenous students.
\end{abstract}

Keywords Nancy Fraser · Indigenous students · Mathematics education · Educators $\cdot$ Selfreflexivity

\section{Introduction}

In this paper, we analyse three sets of round table discussions, from an Indigenous mathematics education conference, to identify the conversational prompts which unfettered understandings about social justice. Our focus on prompts is a response to Fraser's

Tamsin Meaney

tamsin.jillian.meaney@hvl.no

1 Western Norway University of Applied Sciences, Bergen, Norway

2 UiT The Arctic University of Norway, Troms $\varnothing$, Norway

3 University of Regina, Regina, Saskatchewan, Canada 
(2005) highlighting of the need for "participatory parity" (p. 5). For her, "overcoming injustice means dismantling institutionalized obstacles that prevent some people from participating on a par with others" (p. 5). These obstacles could be economic structures, but they could also be "institutionalized hierarchies of cultural value that deny them the requisite standing" (p. 5). For non-Indigenous people, such as ourselves, there is a need to learn how to better ally ourselves so that participatory parity can be achieved. Matthews et al. (2005) emphasised that "there is a role for non-Indigenous people to raise understanding of Indigenous culture amongst non-Indigenous people" (p. 515), but this requires non-Indigenous educators to know how to listen to and understand Indigenous peoples' views on mathematics education (Matthews et al., 2003; Matthews et al., 2005; Howard \& Perry, 2007).

For those who wish to ally themselves with Indigenous peoples' aspirations, it is important to identify how Indigenous colleagues use conversational prompts to share their knowledge, skills and values in ways that they feel comfortable. As an instructional method, prompting tends to happen through the use of simple questions, incomplete sentences, execution of instructions or pictures and graphics (Ifenthaler, 2012). However, in everyday conversation, other kinds of prompts are used. Identifying the conversational prompts that raise different social justice issues provides ways to gain insights into the impact of mathematics education on Indigenous students and how it could be changed through the enactment of participatory parity.

Participatory parity is, therefore, not about everyone contributing equally, but about understanding how different roles contribute to meaningful and relevant views being raised on a particular topic. Alongside Indigenous colleagues, non-Indigenous educators, such as ourselves, work under the same rules and governance structures for the provision of mathematics education, which for Fraser (2008) is a necessary condition for participatory parity. Yet, Fraser (2008) also highlighted that the "what" and the "how" of different issues of social justice affect "who" should participate in these discussions. In the next section, we describe Fraser's $(2005,2008)$ distinction between normal and abnormal social justice and how this distinction relates to the provision of mathematics education for Indigenous students.

\section{Fraser's theory of social justice and mathematics education for Indigenous students}

Although Fraser $(2005,2008)$ continues to develop her theory of social justice in relationship to how nation states grapple with social movements, such as globalisation and multiculturalism, in the last decade, it has also come to be used in educational research (Cazden, 2012). In the background to her theory, Fraser (2005) highlights how the oncetaken-for-granted "Keynesian-Westphalian frame" (p. 69) of social justice is being questioned and destabilised. The Keynesian-Westphalian frame has produced a normalisation of social justice discourses, by assuming that governments of nation states have the right to determine which economic resources are the most appropriate to distribute and how the culture of different groups should be valued or utilised within the wider society.

Fraser (2005) emphasised the importance of political representation-who gets to determine (government) policies about whom? As a result, she described the notions of distribution, recognition and representation in a three-dimensional (socio-economic, cultural 
and political) theory of justice, whereby "the three dimensions stand in relations of mutual entwinement and reciprocal influence" (p. 79). Fraser (2008) described discussions about the economic distribution of resources connected to class and ethnicity as normal justice discourse and proposed that those who dissent from this view of justice are usually marginalised or suppressed:

Justice discourse is normal just as long as public dissent from and disobedience to its constitutive assumptions remains contained. As long as deviations remain private or appear as anomalies, as long as they do not cumulate and destructure the discourse, the field of public-sphere conflicts over justice retains a recognizable, hence a "normal" shape. (p. 394)

Nevertheless, Fraser (2008) considered that discussions of social justice issues are unlikely to remain normal because "whether the issue is redistribution, recognition, or representation, current disputes evince a heteroglossia of justice discourse, which lacks any semblance of normality" (p. 396). Although this unfettering of normal justice is part of an ever-changing society, for alternative or "abnormal" justice to be incorporated into societal practices, contributors to the discussion need to gain credence from a wider group by being heard and understood on their own terms, and hence, the importance of participatory parity. As non-Indigenous educators, we consider identifying conversational prompts that lead to abnormal justice discourses as important for supporting us to listen more respectfully and, thereby, contribute to supporting the aims and aspirations of Indigenous people.

Recently, Fraser's $(2005,2008)$ theory of social justice has been used in mathematics education, particularly in regard to challenging expectations about Indigenous student's learning of mathematics (see Meaney et al., 2016; Trinick, 2019; Nolan, 2020). In this case, economic distribution from the perspective of normal, Keynesian-Westphalian, justice discourse focuses only on equal distribution of Western mathematical knowledge, or "near-universal, conventional mathematics or NUC-mathematics" (Barton, 2008, p. 10). The distribution of this mathematics occurs through schooling by expecting teachers to provide the mathematics education stipulated in national curriculums, most of which look remarkably similar (Meaney, 2018). This normal justice discourse leads to a focus on the gap in Indigenous peoples' standardised test results when compared with their non-Indigenous peers (see Meaney et al., 2012 for the case in Australasia). As a result, Indigenous students are consistently represented as under-achievers in mathematics (Meaney et al., 2012). For example, in Canada, Nicol, et al. (2013) noted that "Aboriginal students tend to be over-represented in special education classes and low-track mathematics courses and under-represented in higher level mathematics courses... and careers that use mathematics" (p. 73). In Norway, Indigenous (Sámi) students score below average on national tests in mathematics in lower secondary school (Fyhn \& Nystad, 2013). With the acceptance of the importance of distributing Western mathematics, social justice aims are focused on determining why mathematics achievement of all students is not equal and how to "catch-up" Indigenous students.

Bishop (1990) argued that when Western mathematics is accepted as necessary for progress, it is situated in school curricula as objective, context-free and culturally neutral. Consequently, Western mathematics curricula can be considered "part of a deliberate strategy of acculturation-intentional in its efforts to instruct in 'the best of the West', and convinced of its superiority to any indigenous mathematical systems and culture" (Bishop, 1990, p. 55). Debates about mathematics education for Indigenous students often assume the superiority of Western mathematics and the application of "Whitestream standards" (Gutiérrez, 2018, p. 2). This presumes a need to "help students 'play the game' of 
mathematics" as opposed to realizing "the need to "change the game' of mathematics" (Gutiérrez, 2018, p. 1).

According to Trinick and May (2013), Indigenous peoples, their culture and language are frequently in subordinate positions in schools and curricula, with national priorities often focusing on Western societal needs and aspirations. In Norway, Keskitalo (2009) highlighted that the Sámi (Indigenous) school system is based on ideas from the sociopolitically, dominant school system, resulting in teaching reflecting a Western view of mathematics.

In her theory of social justice, Fraser (2005) highlighted the need for recognition of cultural backgrounds. Normal justice discourses based on the distribution of NUC-mathematics provide little opportunity for the incorporation of Indigenous culture. Yet, when the value of distributing NUC-mathematics is queried, often the integration of students' cultural background into mathematics education is promoted.

Fraser $(2005,2008)$ stated that participatory parity requires an understanding about who is making decisions about the provision of an economic benefit, in our case mathematics education, for whom. Therefore, the third aspect of Fraser's $(2005,2008)$ theory of social justice is a focus on representation. When the need to gain Western mathematics for future careers within the dominant socio-political society takes precedence (Trinick \& May, 2013), especially in government policies, then Indigenous communities have limited self-determination. Similarly, incorporating cultural recognition into the teaching of mathematics cannot be achieved appropriately without the involvement of community members (see, for example, Meaney et al., 2021).

Although participatory parity is essential if improvements in mathematics education for Indigenous students are to be achieved, there is little research on the ways that Indigenous and non-Indigenous educators interact. Generally, research on non-Indigenous educators working in Indigenous mathematics education focuses on the reflections on individuals (see, for example, Meaney, 2004; Domite, 2010). Based in Canada, Nicol et al. (2020), as a group of Indigenous and non-Indigenous teacher educators, analysed their own narratives in a study group, but the interactions were not investigated. Yet, participatory parity requires non-Indigenous educators to understand how abnormal justice discourses are raised in discussions with their Indigenous colleagues. This can only happen if Indigenous and non-Indigenous educator interactions are better understood.

Supporting the provision of mathematics education which better reflects the aspirations of Indigenous people requires non-Indigenous educators to have reflexivity about the underlying assumptions in discussions (Aguirre et al., 2017; Meaney, 2004). An example of such reflexivity occurred in Norway when Sámi (Indigenous) mathematics teachers recognised that the national written exam disadvantaged their students. In response, they developed and established a culturally responsive, local, oral mathematics exam (Fyhn et al., 2016). Its implementation resulted in students who earlier were glancing out the window with their feet on the desk, instead initiating discussions and taking charge of the mathematics group work, something the teachers felt they had not seen before. Such reflexivity can only happen if Indigenous people are listened to respectfully. All too often as Domite (2010) stated, non-Indigenous educators "other" the experiences of Indigenous educators, because it does not fit Western understanding of pedagogical practices:

We, as teacher educators, have a poorly developed 'listening'. In general, we, as teacher educators, formed by the non-indigenous school are not prepared to listen and then, speak with the 'other'. In fact, when emphasizing the listening on the part of the involved educator with the indigenous teacher, we are in opposition to the 
pedagogical actions that spin around the explanations or in which the questions for the indigenous teachers already come formulated by the educator/teacher educator, in general external to the indigenous culture-an environment in which the educator/ teacher educator does very little 'listening' to the teachers or looks for interacting with the questions posed by them. (p. 309)

By understanding how Indigenous peoples use conversational prompts to raise and sustain issues of importance, non-Indigenous educators can better understand how to ally themselves and contribute to participatory parity. In analysing three sets of discussions between Indigenous and non-Indigenous educators, our research questions are: (1) what conversational prompts provided opportunities for Indigenous participants to raise alternative social justice issues? (2) What aspects of the discussions then supported participants to continue exploring these social justice issues?

\section{Background and methods}

The data were collected at IndigMEC, an Indigenous mathematics education conference, held in Troms $\emptyset$, Norway, in September 2017. The main aim of the conference was for Scandinavian educators to present examples of culturally responsive mathematics teaching, particularly from work carried out with Sámi students. The conference website highlighted that similar work was undertaken with Indigenous students in other parts of the world.

At the conference, Indigenous and non-Indigenous participants-researchers, teacher educators, teachers and preservice teachers from Scandinavia, America (North and South) and Australasia - joined one of three round table groups. The three plenary lecturers were in separate groups, as were the authors, and each group was led by a researcher. Participants joined a group by writing their names on one of three lists, where they could see who else had signed up. Each group had between 12 and 14 members, with the number of Indigenous participants varying from 4 to 8 .

At the beginning of the first session, group members were asked if they agreed to be audio-recorded. Audio-recordings, totalling approximately 6 hours in length, were collected from the two round table sessions.

A presentation of our initial findings was made at the 6th International Ethnomathematics Conference in July 2018, where several participants from the original Indigenous mathematics education conference were present. As a result of feedback, participants' approval for the data from the round table discussions to be used in this way was sought more formally. Once examples were chosen for inclusion in the article, participants were again contacted to ensure that they agreed to the inclusion. Adjustments were made to the transcriptions to ensure that participants were confident in how their contributions were described.

Only a few references to Sámi culture are included in the extracts. Specific references to other Indigenous peoples or languages were reduced to anonymise the data. Although we recognise that this decision has led to a loss of contextual information, the mathematics education community working with Indigenous communities is small, making speakers easily identifiable. As our focus was on conversational prompts and not on the alternative views of justice being provided, it was felt that concerns about anonymisation overrode the need for extra contextual information. All names are pseudonyms and are given prefixes I and NI to distinguish between Indigenous and non-Indigenous individuals, respectively.

The discussion questions for the round table session were presented in English and North Sámi (see Fig. 1 for an example of this dual language presentation), with the plenary 


\section{Overarching themes}

\author{
-What is mathematics? \\ - What are the important things \\ to consider in teaching \\ mathematics to Indigenous \\ students? (what is the response \\ to the question that is constantly \\ asked about what is different \\ about teaching mathematics to \\ Indigenous students)
}

- Mii lea matematihkka?

- Maid beliid lea dehálaš vuhtii váldit go oahpaha ohppiid geain lea eamiálbmot duogáš? (Mii lea vástádus dan agálaš jearaldahkii: Mii lea erohus eamiálbmogii gullevaš ohppiid oahpaheamis ja ohppiid oahpaheamis gean ii leat eamiálbmot gullevašvuohta?

Fig. 1 Overarching themes for the first round table session

speakers from the first 2 days providing additional questions for each session. The conference language was English, but some information like the poster in Fig. 1 was also presented in North Sámi.

The first session began with the question "What is mathematics?" The additional questions were the following:

- How do you implement your students' culture into mathematics education? Or, how do you value and enhance your students' culture in mathematics education?

- How do you make sure their culture is valued?

- How do you put these three words in order: mathematics, language, culture?

The additional question for Session 2 was the following:

- What is the role of mathematics education in decolonizing education and working toward reconciliation?

Group leaders encouraged participants to use their first languages, to assist each other with translations and to speak slowly. They also invited contributions from participants who had not spoken, prior to the sessions ending.

The analysis began with the authors repeatedly reading the transcripts using a "less structured analytic strategy" (Rossman \& Rallis, 2003, p. 298). The individual (re)reading, highlighting and contemplating of transcripts allowed us to identify and then compare discussions that appeared to be about Fraser's (2005) concerns for distribution, recognition and representation. However, as Fraser (2005) noted, these three aspects are intertwined and so within one extract more than one aspect was often visible. This analysis provided an entryway into categorising extracts as being about normal or abnormal justice discourse, before finally identifying the conversational prompts that allowed for the switch from normal to abnormal or a maintenance of that discourse. 
We provide an example of an extract from the first session of group 1 to illustrate how we identified distribution, recognition and representation issues. In it, the teacher I-Carla makes reference to distribution (what form of mathematics as an economically important asset is to be distributed); recognition (whose experiences are valued and should be incorporated into mathematics education); and representation (who should make the decisions about the mathematics education provided to Indigenous students).

I-Carla: We have this idea about there might be other mathematics, yeah. But, I come from the school and I am a teacher and I know that the parents and the government have expectations. And they have a list of what is the mathematics.

This transcript extract was categorised as being about distribution of mathematics, by acknowledging there could be multiple forms of mathematics, but parents and government identified NUC-mathematics, as what students needed. Consequently, social justice was achieved if Indigenous students gained access to NUC-mathematics, which was part of a normal justice discourse. Yet, acceptance of the importance of NUC-mathematics did not always match a normal justice discourse about how Indigenous students should learn:

I-Carla: For me, the starting point is the curriculum and how can I tweak it, so that the pupils actually learn what they are supposed to. Because my experience is that so many of the pupils don't learn the curriculum with the traditional learning style and [with] the examples that are from quite another culture.

We classified this part of her utterance as being about the justice discourse of recognition as it referred to how Indigenous students did not learn through traditional teaching methods, with unfamiliar examples. I-Carla highlighted that a lack of recognition of Indigenous students' backgrounds could contribute to their failure to learn NUC-mathematics. As this example shows, discussions about social justice issues can query some aspects, while simultaneously accepting other aspects.

At the end of her contribution, I-Carla indicated that for her to focus on adapting teaching practices to benefit her students, it was the responsibility of others to decide what should be the content of what was taught.

I-Carla: Let the mathematicians think about the different mathematics because, for me, it's more practical and convenient to work within the boundaries [of the curriculum].

This was classified as being about representation, about who was making decisions about mathematics for Indigenous students. As an Indigenous teacher, I-Carla wanted to make decisions about pedagogy and not be involved in discussions about other kinds of mathematics. As shown in this example, discussions moved between normal and abnormal justice discourses, connected to the speaker's own experiences, responsibilities and expectations about mathematics education.

Overall, we noticed that normal justice discourses contained assumptions about mathematics being valued as a Western domain of knowledge; teaching mathematics by including cultural examples for the purposes of mathematisation, rather than valuing them in their own right; and that external authorities had the sole right to make decisions about the education of Indigenous students, by determining policies such as curricula. In abnormal discussions, these assumptions, either singly or more often collectively, were queried with alternatives often being raised.

The final part of our analysis was to identify the conversational prompts that seemed to initiate and maintain abnormal justice discourse. The length of time each discussion 
remained focussed on abnormal issues differed; nevertheless, if the discussion included more than one speaker, we considered that the abnormal justice discourse had been maintained. Some conversational prompts that initiated examples of abnormal discourses are described in the next section. The use of ellipses (...) means that the extract was shortened. The transcripts were edited so they would be easier to understand.

\section{Conversational prompts}

The conversational prompts, which shifted the discussions from normal justice discourses to abnormal ones, included using examples from Indigenous cultural heritages and highlighting Indigenous cultural knowledge, through the use of specific pronouns which promoted a sense of unity. Shifts tended to be maintained by using Indigenous metaphors and stories of experience or by pushing the logic used to justify normal justice discourses. The settings for the discussions also affected the use of conversational prompts to both shift and maintain abnormal justice discourses.

The open-ended, round table questions acted as conversational prompts because they could be interpreted in different ways. For example, although the first question, "What is mathematics?", appears to focus on the distribution element of social justice, the groups often discussed who made decisions about mathematics education for Indigenous students, thereby reflecting issues of representation. Participants' responses suggested that openended questions supported participants to bring forward ideas, which they had previously contemplated.

One example of a switch to an abnormal justice discourse was from group 2. When discussing the initial round table question, I-Peter suggested that mathematics was "a way to interpret the world". NI-Martin agreed with this, while also adding that mathematics is "a language in itself because of its symbols", but elaborated on this by stating that "there are different cultures, different representations, but still it's an attempt to represent the world around us". With this statement, there was a shift from only validating NUC-mathematics through the use of symbols to considering it as being something wider, indicating a move towards an abnormal justice discourse. I-Peter reinforced this shift by challenging the idea of mathematics only being valid because of its symbols, by asking whether road signs counted as mathematics. NI-Martin's response with a reference to the use of numbers to express distances then situated NUC-mathematics as what should be distributed, suggesting a normal justice discourse. I-Peter took this opportunity to shift the discussion back towards an abnormal justice discourse, by querying whether Western mathematics should be the only kind of mathematics to be valued and distributed:

I-Peter: There are thousands and thousands of languages ..., in the world and it's the same with maths. There are thousands and thousands of ways to talk, to speak, about maths. The language that you are talking about, this is the impression you give, the language you are talking about is ... the traditional Western view of what mathematics is. And for Indigenous people, that has been detrimental to our knowledge. Our people navigated across vast tracts of the Pacific Ocean without a sextant, without a compass, but they had the knowledge and their materials and tools to do that. But that was not the Western view of maths, so that was not considered mathematical knowledge. So, we must be very careful when we say that "maths is 
language or maths is symbols', it's so much more and it's interpreted differently, by different people. You saw that with the Sámi today. ... The way you talk about the $l a v v u,{ }^{1}$ the maths in there, ... traditional maths would not have seen the maths in there. Anyways, there is so much more to it than just symbols.

In this interaction, a range of conversational prompts were utilised in shifting to an abnormal justice discourse. Early on, descriptions of mathematics were queried indirectly, through suggestions about whether road signs counted as mathematics. This provided a setting for I-Peter to contribute a story about Indigenous people's successful navigation of the Pacific Ocean, without Western scientific knowledge or tools, which challenged assumptions about the importance of NUC-mathematics, as a universal language or set of symbols. He used the pronoun "we" in stating "We must be very careful when we say ...", perhaps to gain others' acceptance of his point. In challenging the idea that NUC-mathematics was intrinsically beneficial to Indigenous students, I-Peter provided examples of Indigenous (mathematical) knowledge from his own as well as Sámi culture. In discussing the Sámi example, he referred to the whole round table group, by using "you" in "you saw that with the Sámi today". He then acknowledged the Sámi members of the group, who had presented a session earlier that day, by stating "the way you talked about the lávvu, the maths in there". In this example, the conversational prompts can be summarised as having a supportive setting, using success stories about Indigenous use of mathematics and referring to the whole group and to the Sámi presenters.

This shift was maintained by others referring to their own Indigenous cultural knowledge. However, the acceptance of the importance of Western mathematics meant that the discussion oscillated between normal and abnormal justice discourses. I-Oswald illustrated this oscillation by using a metaphor from the Yolngu people of North East Arnhem Land about the place where saltwater and freshwater meet (see Watson-Verran \& White, 1993).

I-Oswald: Once they come together, they actually create something that's different. But still recognizing that there are two different systems. And the reasons why they want to know about two separate systems is because there is this thing for Aboriginal people around the world that they were still imposed under this power structure. So if we don't understand both ways, then we are going to disadvantage ourselves.

His example acknowledged the importance of both Indigenous and Western mathematics to Indigenous people. I-Oswald's use of an Indigenous metaphor situated Indigenous mathematics as requiring respect (a recognition aspect of social justice), but this utterance was not as forceful a shift as I-Peter's statement, which had linked to the representation issue of who was making the decisions about the mathematics. In this case, the reference to Indigenous knowledge, alongside Western mathematics, did not act as a prompt to shift or maintain the justice discourse as abnormal. Western mathematics retained its importance because Indigenous people would be disadvantaged without knowledge of it.

Nevertheless, the incorporation of references to Indigenous cultural practices generally acted as a prompt to shift to abnormal justice discourses, particularly in regard to recognition aspects of Indigenous culture. In responding to the last additional question, in the first session in group 1, I-Barbara used personal stories to query the homogeneity of an Indigenous culture and how this may affect the mathematics presented at school:

${ }^{1}$ Lávvu is a Sámi temporary dwelling, similar to the tipi of Native Americans. 
I-Barbara: But what I'm thinking about mathematics, culture, and,- what was the last? Language, - mathematics and culture. Maybe you see Sámi culture as one culture, but in Sámi we have different cultures and I'm a little bit afraid that some of the culture can be dominant and not all the students ... know all [of these]. I have grandchildren ... and they are in the elementary school and I sometimes talk with them and see what they're doing in school, and sometimes I think maybe this reindeer husbandry culture is very dominant. And it [school] should think more broadly about culture. Because the reindeer culture, it's the old culture and it's the culture in Sámi that's most different to the Norwegian culture. And it's easy to take examples from the reindeer culture. And then I talked to one of those at the Sámi school in XXXX who said they had also this bealdu [cultivated land including fields and vegetable gardens], - a garden, which was included in the mathematics education. That's a good example that you also bring in other culture than reindeer.

By querying how Sámi culture was seen in the school system, I-Barbara raised issues about recognition of the diversity within that culture, shifting the discourse to an abnormal one, away from assumptions about the homogeneity of Indigenous cultures. She used conversations with her grandchildren to suggest that the reindeer cultural examples may be inappropriate for some Sámi, but hedged her point with "I think", to indicate that others may not have agreed with her. The initial conversational prompt was the round table questions, but I-Barbara's telling why the choice of examples was important to her personally and to the wider community supported the shift to abnormal justice discourse.

I-Ursula and I-Carla continued the shift by further problematising the homogeneity of Sámi culture:

I-Ursula: Yes. The Sámi culture is very complex and a lot of us actually don't speak Sámi. I think probably most of us don't speak Sámi, so the reindeer husbandry is one part but also the project that the XXXX is doing is actually very good because it's more, it is for areas, so it's education and place also.

I-Carla: I can add to that. They talked about the lávvu this time. But all the nature schools have something like fisheries. It has various elements of culture. But it's very easy to take the lávvu, because as I-Barbara says it's so different.

I-Ursula continued the abnormal discourse of justice by first challenging the idea that all Sámi could speak one of the Sámi dialects (a recognition aspect of social justice). She then restated that there was a need for educational examples which better reflect the place where the students came from. Elaborating on I-Barbara's examples, I-Carla referred back to the example of the lávvu, as being very different to typical Norwegian examples. In addition, she referred to fishing, as a cultural activity from Sámi schools that could also occur in Norwegian schools. By not accepting the typical assumptions about appropriate Sámi examples, these three Indigenous women used examples of misrecognition of Sámi culture to shift to an abnormal justice discourse.

In this example as well as in many others, attending conference presentations together provided a shared background that contributed to other conversation prompts being used, such as narrating stories about cultural practices. In particular, the presentation by the Sámi teachers about the mathematics in the lávvu was a reference point for supporting or problematising issues to do with the teaching of mathematics to Indigenous students. 
Similarly, discussing the use of Indigenous languages in the teaching of mathematics often led to abnormal justice discourses. In group 3, during the first session, participants focused on the use of Indigenous languages for teaching mathematics. This led to an abnormal justice discourse about recognition/misrecognition from comparing different Indigenous languages to an international language, such as English.

I-Emmy: So, I guess a question is then, with maths... do we have to have an [Indigenous language] word for every English word? Like do we have to? .... Because that's kind of what the discussion is about. Right?

NI-Nelly: In the [Indigenous] language..., where I did a workshop in a village... they have words for 'to add two quantities together' or 'to add something to another quantity.' They're different verbs. We don't have those different verbs in English. We have to make a phrase to express that difference. Yeah, I mean, do we? Every time we find a mathematical concept in another language, do we have to add something in English as well?

I-Emmy: Yeah. Exactly.... I think, sometimes we risk trying to make [Indigenous language] match English so that we can teach the maths...in, like an English way, if that makes sense. So, we can teach [Indigenous] students to see the mathematics in an English language way.... Do you get what I mean? Whereas, when you teach it in [an Indigenous language] you get to see the mathematics through an [Indigenous] lens.... So you get to see it in a different way.

Several prompts were used to shift this discussion towards an abnormal social justice discourse. I-Emmy initially challenged the group by asking whether a one-to-one correspondence between mathematics terms in Indigenous languages and English was needed. She used "we" to indicate that she expected others to also agree. By offering a story about her experience, NI-Nelly described how Indigenous languages may be more appropriate for teaching mathematics than an international language like English, and in so doing continued the abnormal justice discourse. This suggests that the conversational prompts used by I-Emmy had supported NI-Nelly to listen respectfully and then to show solidarity by using another example to continue the abnormal justice discourse.

I-Emmy then brought up the impact on Indigenous students of learning NUC-mathematics through English or the impact on an Indigenous language which was made to function as though it was English to teach mathematics. In doing so, she linked recognition to distribution issues, with her questions contributing to the maintenance of the abnormal justice discourse.

During the second day, the round table sessions focused on reconciliation and decolonisation, based on that day's plenary session. In group 2, the Sámi participants were asked about their views on reconciliation and, in particular, what they wanted in terms of a reconciliatory education. These questions prompted an abnormal social justice discourse based on the misrecognition of Indigenous cultures. I-Linda provided an example of colonisation by describing how traditional Sámi castration of male reindeer is forbidden by Norwegian law. Male reindeer are castrated to give them a better chance of survival when they swim through very cold water. From her perspective, the government did not understand how the Sámi carried out these practices. NI-Martin raised the problem of painful castration by an untrained hand and asked whether animals' rights and culture could overlap. Although a legitimate question, this seemed to situate the government as having broader overview of the situation, bringing the discussion back to a normal justice discourse about representation.

I-Linda went on to describe how the government required a vet to do the castration, suggesting the Norwegians would teach the Sámi, shifting the discussion to an abnormal justice discourse. She elaborated on this, "I was talking with an old man and he said, 'I 
have done it all my life and I am 80 years old and I know what I'm doing'". I-Linda proposed that traditional practices like castration would be interesting to discuss with school students, while also acknowledging that the school was not allowed to discuss illegal acts. I-William continued the abnormal discourse, by stating that Sámi were actually only "breaking someone else's law". I-Oswald then provided a similar example of colonisation by sharing a story about Indigenous peoples' food gathering from his part of the world. From his perspective, Indigenous peoples were breaking laws, made by non-Indigenous governments, who did not understand Indigenous cultures.

The initial conversational prompt was the supportive setting, developed from the keynote speaker's question for the second day. This contributed to the Sámi participants being asked about their views on reconciliation, which moved the discussion to an abnormal justice discourse, focused on representational aspects and then linked to recognition aspects. The abnormal discourse was continued with others sharing stories about the impact of colonisation on traditional practices and the dilemmas that Indigenous peoples faced across the world in straddling the Western and traditional cultures.

Listening respectfully to these discussions supported NI-Neil, to gain insights from his Indigenous colleagues and then make connections to mathematics education.

NI-Neil: So, you have the government telling you this is the better way. I was thinking yesterday of the lávvu and if you put it in the context of mathematics as a cone and then you assign the language of mathematics to it, in some ways we are imposing that Western mathematics view, divorcing it from your culture and divorcing it from the story.... So, the process of mathematising, it's my view that we have to be so careful if we are going to mathematise something that comes from a community, to not completely divorce it from that community. Because that is important, or even more important than some generic, generalized representation of it. So, if you're talking about your reindeer, they seem to parallel one another. Here, you have your mathematics telling you how to view this; and here, you have the Norwegian government telling you that you have to have these people [vets] come in.

NI-Neil used "we" when talking about whose responsibility it was to decide what situations could be mathematised using Western mathematics understandings, indicating that this was something that non-Indigenous people had to also be aware of. This was in alignment with Matthews et al. (2005) point that non-Indigenous educators have a role to support Indigenous people's aims and aspirations for mathematics education. His use of "you" acknowledged the importance of the Sámi experience as something that non-Indigenous educators, like himself, needed to more fully understand.

In group 3, the querying of the normal justice discourses occurred with the raising of representational issues, about who was making decisions about what was being taught to whom. NI-Betty explained why Indigenous teachers and communities sometimes rejected incorporating cultural examples into mathematics education because they wanted to have the same opportunities as non-Indigenous people. This reinforced that Western mathematics was the valued mathematics that needed to be distributed to Indigenous students. Yet, based on what he had heard from the Indigenous educators at his round table, NI-Fred then problematised the school system, suggesting it colonised ways of thinking "you have all the questions about where is it [the schooling] going to take place? What is going to be taught? What is not going to be taught? How many adults, how many children?" In this way, NI-Fred began a shift towards an abnormal social justice discourse by highlighting the issue of representation, of who decides on what schooling for whom, and how. This was a 
significant shift from the earlier discussion about the importance of Western for Indigenous students. I-Emmy built on this critique of schooling by presenting the issue, in a joking manner:

I-Emmy: Some say it's mathematics and it is traditional knowledge. And traditional knowledge comes into school and says, 'Excuse me, mathematics, is it OK if I come in?'

I-Emmy: And so, actually, shouldn't it be the other way around? ... Shouldn't the traditional knowledge be the basis of learning anything? And maybe mathematics can come in?

Other group members strongly supported her suggestion of making Indigenous knowledge the basis for what goes on in the classroom to overcome the dominance of NUCmathematics, continuing the abnormal justice discourse that drew on distribution, recognition and representation aspects.

In this example, these personal stories, the pronoun "we", jokes and rhetorical questions, acted as prompts which situated the group as having shared experiences or views. The perceived unity that the prompts provided contributed to the continuation of the abnormal justice discourse developed in this exchange.

\section{Discussion and conclusion}

Our aim for this article was to identify the conversational prompts that could support nonIndigenous educators to learn to listen better (Domite, 2010). Fraser's $(2005,2008)$ theory of social justice supported us to identify abnormal justice discourses, raised by Indigenous colleagues in round table discussions. Abnormal justice discourses occurred when Indigenous participants made explicit or implicit references to aspects of distribution (what kind of mathematics should be distributed), recognition (whose cultural practices should be acknowledged as important and in what ways) and representation (who was making decisions about whom). Often two or more of these aspects were intertwined within the abnormal justice discourses. Identifying abnormal justice discourses allowed us to answer the following research questions: (1) what conversational prompts provided opportunities for Indigenous participants to discuss alternative social justice issues? (2) What aspects of the discussions then supported participants to continue discussing these social justice issues? Identifying the conversational prompts that supported and maintained shifts to abnormal justice discourses provides non-Indigenous educators, such as ourselves, with information about what to listen for and how to listen to Indigenous educators in order to ensure participatory parity.

A variety of conversational prompts were used to shift towards an abnormal justice discourse. First, the setting for the discussions, including being part of a small, dedicated conference, seemed to provide a supportive environment for raising alternative perspectives. For example, I-Linda explored her concerns about what should be and what could be legitimate knowledge both inside and outside schools, without being challenged for how her concerns related to mathematics education. Instead, the sharing of her story led to similar concerns being raised by other Indigenous educators. The round table context allowed for uncertainty to be voiced, which seemed to provide opportunities to either shift or continue within abnormal social justice discourses. 
In previous research on Indigenous educators attending mathematics education conferences, a lack of sense of belonging because of the focus on improving the teaching of Western mathematics and the exoticising of their cultural practices for the benefit of international keynote speakers resulted in many educators excluding themselves from participation (Meaney et al., 2009). In the round table discussions, participants showed a sense of belonging by raising issues that were important to them and using inclusive pronouns. As participants became more familiar with each other during the second day of round table sessions, they began to refer to their groups as a whole, which contributed to developing a consensus on different topics. Some of the participants' prompts were asking for reassurance that the points were understood and the use of the personal pronoun "we" to include the whole group. It seemed that there was an implicit assumption that the participants shared an interest in discussing the issues raised in the round table discussion and often a desire to form a consensus of opinions, at least to some degree.

The open-ended questions provided possibilities to shift the discussions to abnormal justice discourses. For instance, the transcript excerpts illustrated that discussions surrounding "what mathematics is" and "what might reconciliatory education entail" brought up the importance of determining who has the power to decide what (content and form of) mathematics was valued. In this way, Indigenous educators queried assumptions about Western mathematics being necessary for progress (Bishop, 1990). At times, they made direct statements that opposed the dominance of NUC-mathematics or explicitly queried who was deciding what was taught in school. I-Emmy, for example, used a joke format to put forward the opinion that mathematics should be made to adapt to Indigenous knowledge, rather than assuming it must be the other way around. Therefore, for non-Indigenous educators to listen to their Indigenous colleagues, it is important that the setting, including the use of open-ended questions, supports the raising of abnormal discourses. As Risser and Waddell (2018) stated, "Traditional conference formats that do not create opportunities for interaction and engagement between participants could unintentionally prevent professional learning from occurring" (p. 202).

In our analysis, non-Indigenous educators' self-reflection seemed to align with Ifenthaler's (2012) research on the value of generic prompts. The open-ended or more generalised questions, along with use of the inclusive pronouns "we" and "our", encouraged Indigenous colleagues to raise and sustain abnormal justice discourses. By listening for these prompts, non-Indigenous educators could identify what kind of contribution could be added to the discussion, as when NI-Nelly added another story to support I-Emmy's point about the use of Indigenous languages for the teaching of mathematics. NI-Neil's contribution showed that listening to the stories of I-Linda and I-Oswald provided him with an opportunity to reflect on his understanding about mathematising cultural practices, so that Western mathematics could not be imposed on an artefact but instead the artefact should be valued in its own right and from the perspective of what is important Indigenous mathematics. This is in alignment with research on how to respectfully incorporate mathematical ideas into discussions about cultural artefacts (Meaney et al., 2021).

In an article on equity within mathematics education research, Aguirre et al. (2017) wrote about the necessity of mathematics education researchers undertaking reflective work, by "making our ideologies explicit, exploring our lived experiences and identities in relationship to our research and practices, and reflecting on assumptions and decisions we make take work" (p. 126). However, little has been documented about how to undertake that work. Although Aguirre et al. (2017) recommend engaging with colleagues in discussions, the reality for those who work in Indigenous education is that there are few occasions where there is a sufficient critical mass for such discussions to occur. As well, there 
is little work that has been done to identify how alternative views can be brought forth to challenge assumptions about the importance of NUC-mathematics. In this paper, with the permission and support of participants, we used transcripts from two sets of round table sessions to identify conversational prompts which allowed for alternative views of social justice to become evident as a way of overcoming "institutionalized hierarchies of cultural value that deny them the requisite standing" (Fraser, 2005, p. 5) in order to achieve participatory parity.

If non-Indigenous mathematics educators are to act as allies to their Indigenous colleagues, it is important that they understand when and how to listen. For example, stories that drew on Indigenous participants' personal histories were told, not just to elaborate on points being made, but to frame the wider context of the discussions. Identifying conversational prompts, which raised and sustained abnormal justice discourses, provides opportunities for non-Indigenous mathematics educators to listen more appropriately to their Indigenous colleagues. This has the possibility to contribute to self-reflexivity needed for understanding and acting on alternative perspectives of social justice as presented by Indigenous colleagues. Participatory parity requires a capacity to relate ethically, in order for Indigenous sensibilities within mathematics education to be heard and so form the basis for a different kind of social justice for Indigenous students, than the one most often advocated by non-Indigenous educators - the distribution of NUC-mathematics.

Acknowledgements We would like to thank all of the participants who contributed to the round table discussions. Their thoughtful reflections raised many considerations that related to social justice issues within mathematics education, only some of which are described in this paper. As three non-Indigenous mathematics education researchers, we especially acknowledge the role of our Indigenous colleagues in providing valuable input for our learning about how to ally ourselves, particularly in regard to issues of representation.

Funding Open access funding provided by Western Norway University Of Applied Sciences. Funding for the conference came from the Research Council of Norway and was connected to the project "Culturallybased mathematics in Sámi”, also funded by the Research Council of Norway, project 247182.

Open Access This article is licensed under a Creative Commons Attribution 4.0 International License, which permits use, sharing, adaptation, distribution and reproduction in any medium or format, as long as you give appropriate credit to the original author(s) and the source, provide a link to the Creative Commons licence, and indicate if changes were made. The images or other third party material in this article are included in the article's Creative Commons licence, unless indicated otherwise in a credit line to the material. If material is not included in the article's Creative Commons licence and your intended use is not permitted by statutory regulation or exceeds the permitted use, you will need to obtain permission directly from the copyright holder. To view a copy of this licence, visit http://creativecommons.org/licenses/by/4.0/.

\section{References}

Aguirre, J., Herbel-Eisenmann, B., Celedon-Pattichis, S., Civil, M., Wilkerson, T., Stephan, M., ..., \& Clements, D. H. (2017). Equity within mathematics education research as a political act: Moving from choice to intentional collective professional responsibility. Journal for Research in Mathematics Education, 48(2), 124-147. https://doi.org/10.5951/jresematheduc.48.2.0124

Barton, B. (2008). The language of mathematics: Telling mathematical tales. Springer.

Bishop, A. J. (1990). Western mathematics: The secret weapon of cultural imperialism. Race \& Class, 32(2), 51-65. https://doi.org/10.1177/030639689003200204

Cazden, C. (2012). A framework for social justice in education. International Journal of Educational Psychology, 1(3), 178-198.

Domite, M. D. C. S. (2010). The encounter of non-Indigenous teacher educator and Indigenous teacher: The invisibility of the challenges. ZDM-Mathematics Education, 42(3-4), 305-313.

Fraser, N. (2005). Reframing justice in a globalizing world. New Left Review, 36, 69-88. https://newleftreview. org/II/36/nancy-fraser-reframing-justice-in-a-globalizing-world

Fraser, N. (2008). Abnormal justice. Critical Inquiry, 34(3), 393-422. https://doi.org/10.1086/589478 
Fyhn, A. B., JannokNutti, Y., Nystad, K., Eira, E. J. S., \& Hætta, O. E. (2016). "We had not dared to do that earlier, but now we see that it works": Creating a culturally responsive mathematics exam. AlterNative: An International Journal of Indigenous Peoples, 12(4), 411-424. https://doi.org/10.20507/AlterNative.2016. 12.4 .6

Fyhn, A. B., \& Nystad, K. (2013). Sami culture and values: A study of the national mathematics exam for the compulsory school in Norway. Interchange, 44, 349-367. https://doi.org/10.1007/s10780-013-9201-3

Gutiérrez, R. (2018). The need to rehumanize mathematics. In I. Goffney, R. Gutiérrez, \& M. Boston (Eds.), Annual perspectives in mathematics education: Rehumanizing mathematics for Black, Indigenous, and Latinx students (pp. 1-10). The National Council of Teachers of Mathematics.

Howard, P., \& Perry, B. (2007). A school-community model for enhancing Aboriginal students' mathematical learning. In J., Watson, \& K., Beswick (Eds.) Mathematics: Essential research, essential practice, Proceedings of 30th Mathematics Education Research Group of Australasia (pp. 402-411). MERGA.

Ifenthaler, D. (2012). Determining the effectiveness of prompts for self-regulated learning in problem-solving scenarios. Educational Technology \& Society, 15(1), 38-52.

Keskitalo, J. H. (2009). Sámi máhttu ja sámi skuvlamáhttu: Teorehtalaš geahčastat [Sámi knowledge and Sámi school knowledge: A theoretical perspective]. Sámi dieđalaš áigečála, 9(1-2), 62-75. http://site.uit.no/ aigecala/sda-1-2-2009_keskitalo/

Matthews, S., Howard, P., \& Perry, B. (2003). Working together to enhance Australian Aboriginal students' mathematics learning. In L. Bragg, C. Campbell, G. Herbert, \& J. Mousley (Eds.), Mathematics education research: Innovation, networking, opportunities: Proceedings of the 26th Annual Conference of the Mathematics Education Research Group of Australasia (pp. 9-28). MERGA.

Matthews, C., Watego, L., Cooper, T., \& Baturo, A. (2005). Does mathematics education devalue Indigenous culture? Indigenous perspectives and non-Indigenous reflections. In P., Clarkson, A., Downton, D., Gronn, M., Horne, A., McDonough, R., Pierce, \& A., Roche (Eds.), Building connections: Research, theory and practice, Proceedings of the 28th Mathematics Education Research Group of Australasia (pp. 537-544). MERGA.

Meaney, T. (2004). What's power got to do with it? In M. Walshaw (Ed.), Mathematics education within the postmodern (pp. 181-200). Information Age Publishing.

Meaney, T. (2018). Mathematics curricula: Issues of access and quality. In M. Jurdak \& R. Vithal (Eds.), Social and political dimensions of mathematics education (pp. 171-189). Springer.

Meaney, T., Trinick, T., \& Fairhall, U. (2009). The conference was awesome: Social justice and a mathematics teacher conference. Journal of Mathematics Teacher Education, 12(6), 445-462. https://doi.org/10.1007/ s10857-009-9122-3

Meaney, T., McMurchy-Pilkington, C., \& Trinick, T. (2012). Indigenous students and the learning of mathematics. In B. Perry, T. Lowrie, T. Logan, A. MacDonald, \& J. Greenlees (Eds.), Research in mathematics education in Australasia 2008-2011 (pp. 67-88). Sense Publications.

Meaney, T., Edmonds-Wathen, C., McMurchy-Pilkington, C., \& Trinick, T. (2016). Distribution, recognition and representation: Mathematics education and Indigenous students. In K. Makar, S. Dole, J. Visnovska, M. Goos, A. Bennison, \& K. Fry (Eds.), Research in Mathematics Education in Australasia 2012-2015 (pp. 143-164). Springer.

Meaney, T., Trinick, T., \& Allen, P. (2021). Ethnomathematics in education: The need for cultural symmetry. In M. Danesi (Ed.), Handbook of cognitive mathematics. Springer. https://doi.org/10.1007/978-3-030-449827_4-1

Nicol, C., Archibald, J. A., \& Baker, J. (2013). Designing a model of culturally responsive mathematics education: Place, relationships and storywork. Mathematics Education Research Journal, 25(1), 73-89. https:// doi.org/10.1007/s13394-012-0062-3

Nicol, C., Gerofsky, S., Nolan, K., Francis, K., \& Fritzlan, A. (2020). Teacher Professional learning with/in place: Storying the work of decolonizing mathematics education from within a colonial structure. Canadian Journal of Science, Mathematics and Technology Education, 20, 190-204.

Nolan, K. (2020). Conceptualising a methodology for reframing mathematics/teacher education through a new (disruptive) form of culturally responsive pedagogy. In P. J., White, R., Tytler, J., Ferguson, \& J. C., Clark (Eds), Methodological Approaches to STEM Education Research Volume 1, (pp. 133-153). Cambridge Scholars Publishing.

Risser, H. S., \& Waddell, G. (2018). Beyond the backchannel: Tweeting patterns after two educational conferences. Educational Media International, 55(3), 199-212.

Rossman, G. B., \& Rallis, S. F. (2003). Learning in the field: An introduction to qualitative research. Sage Publications.

Trinick, T. (2019). Mathematics education: Its role in the revitalisation of Indigenous languages and cultures. In J., Subramanian (Ed.) Proceedings of the tenth international mathematics education and society 
conference (vol. 1). University of Hyderabad. http://mes10.uohyd.ac.in/mes/program/conferenceProce edings.php

Trinick, T., \& May, S. A. (2013). Developing a Maori language mathematical lexicon: Challenges for corpus and status planning in indigenous contexts. Current Issues in Language Planning, 14(3-4), 457-473. https://doi.org/10.1080/14664208.2013.835149

Watson-Verran, H., \& White, L. (1993). Issues of knowledge in the policy of self-determination for Aboriginal Australian communities. Knowledge and Policy, 6(1), 67-78.

Publisher's note Springer Nature remains neutral with regard to jurisdictional claims in published maps and institutional affiliations. 